\title{
Science advisory role of national science academies
}

AUTHORS:

Roseanne Diab

Susan Veldsman' ${ }^{1}$

\section{AFFILIATION:}

${ }^{1}$ Academy of Science of

South Africa, Pretoria,

South Africa

\section{CORRESPONDENCE TO:} Roseanne Diab

EMAIL:

roseanne@assaf.org.za

POSTAL ADDRESS:

Academy of Science of South Africa, PO Box 72135 ,

Lynnwood Ridge 0040, South Africa

\section{KEYWORDS:}

science advisory ecosystem; evidence-based advice; consensus studies; evidence-informed policy

\section{HOW TO CITE:}

Diab R, Veldsman S. Science advisory role of national science academies. S Afr J Sci. 2016;112(7/8), Art. \#a0169, 3 pages. http://dx.doi. org/10.17159/sajs.2016/a0169

(C) 2016. The Author(s). Published under a Creative Commons Attribution Licence.

\section{Rising global interest in science advice}

The celebration of the Academy of Science of South Africa's (ASSAf's) 20th anniversary presents an opportune time to examine ASSAf's role in the science advisory space in South Africa and to reflect, more generally, on the nature and value of academy advice. Although very young in comparison with other global science academies, some of which are more than 360 years old, ASSAf is fortunate to have benefitted from the experience of others and since its inception has had its science advisory role clearly articulated in its statutes. This is not true of many of the older science academies that were founded with the intention of fulfilling a largely honorific role and as such have had to grapple with the transition to a working academy model.

The topic of science advice is assuming a rapidly evolving and increasingly prominent role. The importance of science advice is commonly attributed to the scientific nature of the challenges confronting modern society examples include climate change, disaster risk management, food security, and the bulk of the 17 Sustainable Development Goals. However, a defining moment in this newfound prominence must be attributed to the workshop on science advice hosted by Professor Sir Peter Gluckman, Chief Science Advisor (CSA) to the Prime Minister of New Zealand, under the auspices of the International Council for Science (ICSU) General Assembly in Auckland, New Zealand in August 2014. Further interest has been stimulated by the creation of the International Network of Government Science Advice (INGSA), led by Gluckman.

Science advice has also been the topic of international meetings hosted by ASSAf. These meetings include the InterAcademy Partnership (IAP) General Assembly and conference hosted by ASSAf in February 2016 in Hermanus; the capacity building workshop on science advice for African scientists that was held as a pre-event to the IAP meeting; and a South African Young Academy of Science (SAYAS) event on youth perspectives on science advice to governments that was held in March 2016 alongside the IAP meeting. All these events have placed the spotlight on science advice and raised awareness amongst scientists and policymakers.

\section{Science advisory ecosystem}

A useful concept is that of a science advisory ecosystem, which accommodates a range of co-existing science advisory modalities, with individual models assuming varying importance in different countries, giving rise to ecosystems that may have quite different geographical expressions. Some of these science advisory modalities may include individual scientists, industry and/or business groupings, non-governmental organisations, science and technology committees, statutory bodies mandated to provide advice, government scientists, national academies and CSAs. ${ }^{1}$

A variety of advisory structures is in place in South Africa, which include those listed above, as well as others such as advisors in individual ministries, sector-specific advisory bodies and early warning advisory bodies. ${ }^{2}$ It is therefore not difficult to understand why in South Africa, the term 'crowded advisory space' is often used.

Here we focus on the role of science academies in this ecosystem, highlight the strengths of academy advice, give some examples from ASSAf's experience and reflect on how academy advice might evolve in the future in the South African context.

The academy's niche in the science advisory space is clearly carved out. Its strength lies in long-term, indepth, evidence-based studies known in academy parlance as 'consensus studies'. Consensus studies are executed by a panel of volunteer members (not necessarily academy members/fellows). The panel members are selected for their knowledge and excellence in the field, their willingness to serve in a volunteer capacity and in the South African context, with due consideration given to demographic diversity. Consensus studies are a unique academy methodology, providing a multi-perspective, evidence-based view on a particular topic. Findings and recommendations are synthesised and published in a peer-reviewed report that is made available in the public domain.

ASSAf's experience in implementing consensus studies was gained from the United States National Academies during the African Science Academy Development Initiative (ASADI), which was a long-term capacity development initiative that introduced ASSAf to many such activities. It is acknowledged that the term 'consensus study' is troubling to some, particularly scholars in the humanities. However, the term should not be perceived as a notion that may stifle or constrain rigorous debate and argument, but rather as a means to distill core points of agreement that can provide policymakers with some degree of certainty about the complex world in which we live.

\section{Addressing uncertainty in a complex, post-normal world}

It is acknowledged that the complexity of the space in which science advisory bodies are operating can be overwhelming. This state was pointed out by Gluckman ${ }^{3}$ when referring to a post-normal world, characterised by uncertainty and stochastic phenomena. The need to reach consensus on key findings and recommendations in such complex situations is critical when giving advice to policymakers. At no time in our history has the need to identify the core been more urgent. Faced with an overwhelming amount of information and complexity, the role of academies in distilling the complexity into a finite number of evidence-based recommendations agreed upon by a panel of experts, is critical. 


\section{Challenges facing academies in giving science advice}

Some of the challenges faced by academies in giving advice are those of relevance, timeliness and receptivity. If an academy-initiated consensus study does not align with the current needs of policymakers, it may be relegated to dusty bookshelves. This does not necessarily imply that only studies requested by government should be undertaken. On the contrary, it is expected that academicians will be sufficiently alert and practised in their fields that they will be able to identify emerging topics and embark on studies that will be useful to policymakers regardless of the genesis. Relevance also relates to the scope and focus of the study. The findings and recommendations must be precise, concise, targeted and useful. A related challenge is that of timeliness. Ideally, if the timing of a study is right, its relevance will be enhanced.

One of the biggest challenges is that of receptivity or country readiness for science advice. A report will have limited impact on policy if government is either unwilling or unprepared to receive the advice. Perhaps one of the best examples of this scenario is ASSAf's 2007 report HIV/AIDS, TB and Nutrition, which was published when the government at the time held alternative views about the cause of AIDS. The ASSAf report gained no traction in South Africa at the time, despite being lauded abroad as an example of a bold academy report seeking to present the scientific evidence. It is interesting to note that the full impact of this report was only experienced many years after its publication.

A second example is that of ASSAf's 2015 report Diversity in Human Sexuality: Implications for Policy in Africa, which drew some bold conclusions based on recent scientific evidence, and in so doing dispelled many myths surrounding human sexuality. The reception of this report in South Africa, which is known to uphold human rights of all persons regardless of sexual orientation, contrasted dramatically with its uptake in other African countries, $60 \%$ of which have legislation criminalising same-sex sexual conduct and some even have laws by which such conduct is punishable by death. Publishing an evidencebased report that challenges widely held belief systems underpinned by legislation takes courage. In this respect, the Ugandan National Academy of Sciences (UNAS) is to be commended for their courageous stance in the face of severe government opposition to the findings in the report. For ASSAf it was less of a reputational risk as the findings concurred with generally held views in the country. Exceptionally disconcerting, however, was the large number of science academies in Africa that refused to endorse the evidence-based report, in all probability because the evidence challenged official government positions or belief systems in those countries. Such a situation in which so few are willing to tackle a controversial topic and uphold the evidence base, does not bode well for academy advice in Africa.

\section{Impact of ASSAf consensus study reports}

To date ASSAf has conducted 19 consensus studies, all of which are available on the ASSAf website. A question that is often asked relates to the impact and uptake of these reports. Recently, ASSAf has introduced a monitoring and evaluation framework and has begun to track impact, although it is acknowledged that this is a complex undertaking that is still in its infancy. Some examples of a direct policy influence of ASSAf's reports are listed:

- The 2006 Report on a Strategic Approach to Research Publishing in South Africa and the 2009 report Scholarly Books: Their Production, Use and Evaluation in South Africa Today had a major influence on the Research Output Policy of the Department of Higher Education and Training (DHET) that was published in 2015 and implemented with effect from January 2016. Recommendations from each of these reports have been incorporated into the DHET policy, specifically those relating to quality, peer-review practices, subsidy units allocated for books, and the inclusion of Scientific Electronic Library Online (SciELO)-SA as an index for automatic accreditation of South African scholarly journals.
- The findings and recommendations of the 2010 report, entitled The PhD Study, were used by the Council for Higher Education as a basis for discussion when revising the Higher Education Qualifications Framework. The report recommendations were also implemented by the Department of Science and Technology, DHET and the National Research Foundation.

- The 2009 report Revitalising Clinical Research in South Africa led to announcements by the Minister of Health regarding increased health research funding and a website has been developed to raise awareness about and promote clinical research in South Africa.

\section{Limitations of science advice in the policymaking process}

Policy is rarely determined by scientific evidence alone. It is contended that to some extent the provision of advice may be viewed as separate from the policymaking process. The advice that is given should be based on the best available information which underpins objective conclusions and recommendations to policymakers. That a policymaker may elect on occasions not to follow the advice given must be acknowledged. There may be many competing and compelling considerations that have little to do with the scientific evidence, such as financial constraints, public opinion and political obligations. Gluckman ${ }^{3}$ therefore prefers the term evidence-informed policy as opposed to evidence-based policy.

\section{Advice versus advocacy}

Advocacy differs from objective, impartial science advice in that it reflects the interests and/or value systems of the party providing the information. Ideally, the body providing advice in this instance should be transparent about their bias and how it may influence the conclusions reached; non-governmental organisations typically fall into this category. Such responsible, science-based advocacy differs from science advice but may still have a place. ${ }^{1}$

Straying into the advocacy terrain is dangerous for academies. At the heart of academy advice is the reputation for honest, objective, unbiased advice. Damage to these core attributes would place the advisory function at risk and render academy advice questionable.

\section{Confidentiality of science advice}

There is certainly a need for confidential science advice, but this is not a role that is or should be fulfilled by academies. Academy advice is valued for its transparency; all ASSAf's science advisory reports are published and available in the public domain. Arguably there are other bodies that are more suited to this type of science advice and the distinction between such bodies and academies in respect of their science advisory roles should remain - further strengthening the notion of a science advisory ecosystem and a distinct but synergistic role for all the ecosystem components.

\section{ASSAf's role in science advice in the future}

The two main bodies mandated to provide science advice in South Africa - ASSAf and the National Advisory Council on Innovation (NACl) - have each defined their niche and form part of the science advisory ecosystem in the country. The former focuses on long-term, in-depth studies as described above and the latter on shorter timescale studies of the order of a few months and produces concise briefs for the Minister of Science and Technology. There is a gap at the very short end of the temporal spectrum, when advice is required on a timescale of the order of days or weeks.

It is generally acknowledged that academies are not good at providing rapid response advice. The question might then be posed as to who is best positioned to give rapid response advice. Certainly, a CSA can play a critical role and in times of disasters or emergencies may even become part of the decision-making team as noted by Gluckman ${ }^{3}$. However, even a CSA is unlikely to possess all the expertise required at a time that rapid response advice is required and would likely depend on advice from a network of experts in such instances. It is contended that in the absence of a CSA in South Africa, ASSAf should assume this role. Academies 
are renowned for their convening capabilities, largely expressed through the hosting of workshops and symposia. Yet, there is nothing preventing this experience and proficiency from being exercised in a shorter time frame; the same network of national and international experts could be convened electronically or telephonically and either collectively or individually, to seek advice in such situations. Currently, in South Africa, neither ASSAf nor NACl is active in this advisory space. A role for ASSAf should be explored.

\section{Final reflection}

Notwithstanding the fact that ASSAf's role as a science advisory body is enshrined in the ASSAf Act, it is incumbent on ASSAf to mould and establish this role such that its advice is highly respected and sought after. The fundamental tenets of academy advice, essentially objective, evidence based, free of vested interests, based on volunteerism and multi-perspective, must be cherished and protected as ASSAf matures in its role in the science advisory ecosystem in South Africa.

\section{References}

1. Hutchings JA, Stenseth NC. Communication of science advice to government. Trends Ecol Evol. 2016;31(1):7-11. http://dx.doi.org/10.1016/j. tree.2015.10.008

2. Netshiluvhi T. Overview: Africa's science advice landscape. Proceedings of the Science Advice for African Scientists' Workshop; 2016 February 26-27; Hermanus, South Africa. Pretoria: ASSAf; 2016. p. 5-7. In press 2016.

3. Gluckman P. Keynote address. Proceedings of the InterAcademy Partnership (IAP) Conference on Science Advice; 2016 February 28 - March 01; Hermanus, South Africa. Pretoria: ASSAf; 2016. p. 6-8. In press 2016. 